\title{
A Bernoulli-Geostrophy Weather Event
}

\author{
Kern E. Kenyon \\ 4632 North Lane, Del Mar, CA, USA
}

Correspondence to: Kern E. Kenyon, kernken@aol.com

Keywords: Bernoulli, Geostrophy, Wind Storm

Received: March 30, $2019 \quad$ Accepted: April 20, 2019

Published: April 23, 2019

Copyright $\odot 2019$ by authors and Scientific Research Publishing Inc.

This work is licensed under the Creative Commons Attribution International License (CC BY 4.0).

http://creativecommons.org/licenses/by/4.0/

\section{(c) $\underset{\mathrm{BY}}{\mathrm{BY}}$ Open Access}

\section{ABSTRACT}

One rainstorm over the North Pacific is studied and compared to a single dynamic fluid flow equation in order to see what measure of agreement might occur. Meteorological data for the rain storm come from the bridge of an oceanographic ship that sailed from San Diego to Japan along $35^{\circ} \mathrm{N}$ in the spring of 1976 [1]. A single dynamic equation originated from combining Bernoulli's law with the geostrophic relation and eliminating the pressure between them [2]: horizontal wind shear equals the Coriolis parameter. Wind speed measured on the ship every two hours is used to compute the mean wind shear over the 48 hours of the rain storm. That shear has the right sign and order of magnitude to agree with the Coriolis parameter at $35^{\circ} \mathrm{N}$.

\section{INTRODUCTION}

After the valuable and very accurate hydrographic data had been gathered, which was the main reason for the oceanographic cruise in the first place, then they had been processed and published, and analyses of them had begun; there remained the meteorology data. Normally those would not be looked at by anybody because of the low quality of the data and for other reasons [Ocean temperatures were measured to the nearest $1 / 100$ of a degree ${ }^{\circ} \mathrm{C}$, air temperatures to the nearest 1 degree F]. Being trained as an oceanographer, I probably would not have bothered about them either except for a comment from the person in the office next door (at SIO) which intrigued me. He said a Japanese researcher many years before had discovered a noon minimum in air temperature at sea level off the east coast of Japan. It is a very curious feature to be sure.

Soon after I found a noon minimum in air temperature from the cruise data, and it was more prominent than what the Japanese scientist had discovered, although it did not occur every day, but in about $1 / 3$ of the total of 35 days. One thing led to another and out popped a signal in the air temperatures with a time scale of two days! That was not looked for and totally unanticipated. In fact, all the quantitative weather data put down in the Captain's Log book on the bridge of the ship exhibited the two-day signal, and in most cases it was larger in amplitude than that of the diurnal (or one day) signal [1].

To improve on the exposition of the two-day oscillation, the raw data were subjected to a two-step 
smoothing process involving 13 and 25 point running means. Quite a few years later it was noticed that the two-day variations of pressure and wind speed were anti-symmetric such that when the speed was high, the pressure was low and vice versa throughout almost all of the two records. That got me thinking there might be a Bernoulli's law at work within these particular weather features [3]. So the smoothing method apparently brought out the potential for the Bernoulli law relation, but on the other hand as will be seen below, it wiped away any existing asymmetry in the shape of the southward cold pulses of wind speed.

\section{DATA}

Figure 1 shows the wind speed in nautical miles per hour for every two hours local time throughout the 48 hour rain storm. Midnight of March 29/30 is on the far left and midnight of March 31/Aprill is on the far right. It is seen that from hour 6 to 8 on March 30 the wind speed jumped from 12 to 30 kts. From there in the mean the wind speed steadily dropped to $5 \mathrm{kts}$ over the remainder of the record presented. Since the ship alternated between stopping on station and steaming between stations, converting the horizontal time axis of Figure 1 to a distance scale is a little difficult. However, in the Captain's Log the positions of the ship are given three times per day. The west longitudes and local times for March 30 are: 134 02.0 at $0630,134-56.0$ at 1200, and $136-02.5$ at 1925, and those for March 31 are: $137-00.9$ at 0614,138 00.0 at 1200 , and $137-58.0$ at 1736 . Latitudes are all very close to $35^{\circ} \mathrm{N}$. Oceanographic stations were made every whole degree of longitude, spaced $91 \mathrm{~km}$ apart.

In Figure 2 the wind direction for the rain storm is displayed in degrees from which it was blowing, such that 0 means the wind is straight out of the north. It can be seen in the figure that between hour 6 and 8 local time on March 30 the wind direction suddenly changed to being out of the north. From then on the direction more gradually (on the average) rotated to be more from the east.

Air temperatures (the dry bulb values) during the storm are selected as the last piece of data in Figure 3 because they speak to the cause of the high winds. There was a lot of relatively cold air at sea level, in the middle of the storm, which evidently must have originated further to the north, pushing the lighter warmer air out of the way in the process.

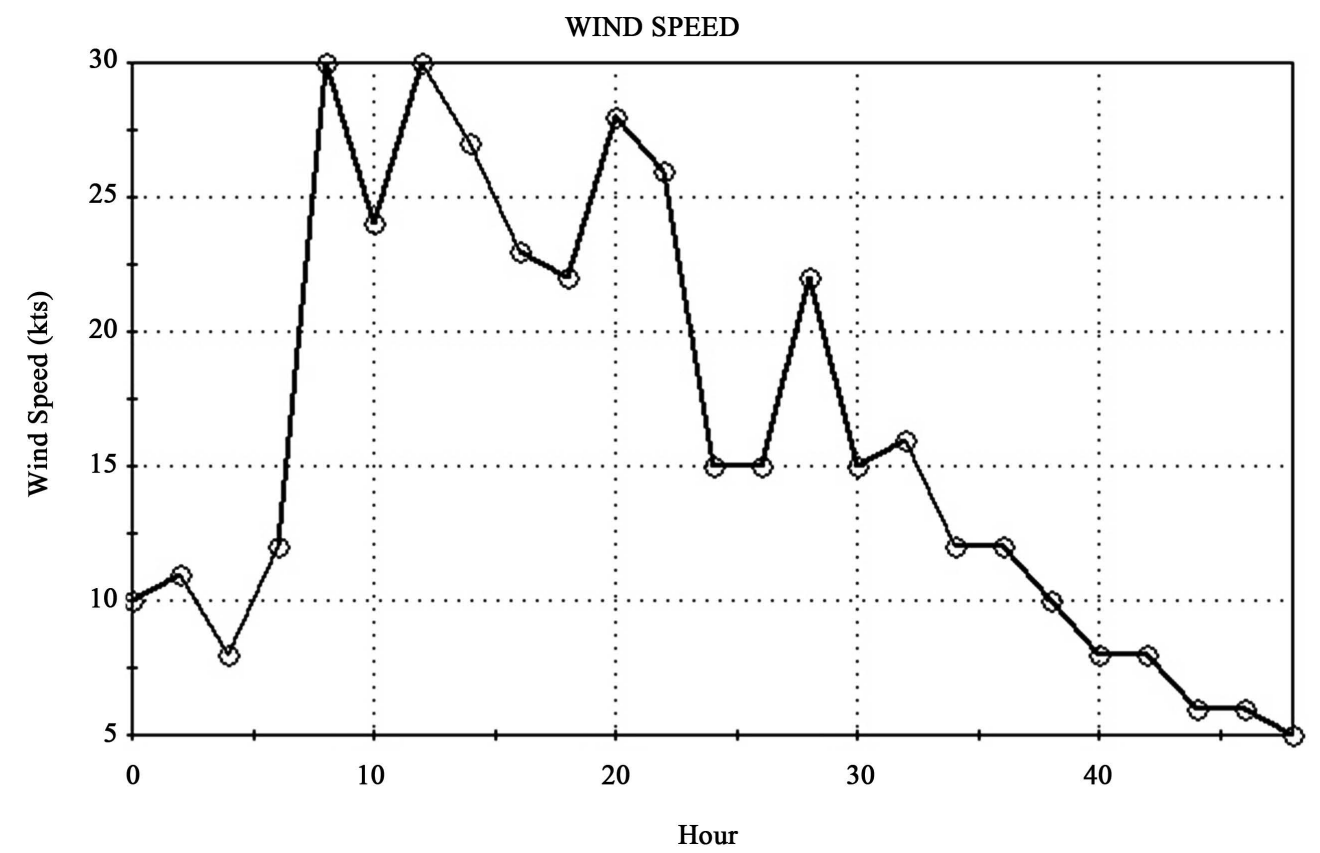

Figure 1. 48 hour wind speed record starting at midnight March 29/30, 1976 from a ship moving west along $35^{\circ} \mathrm{N}$ from $133^{\circ} \mathrm{W}$. 


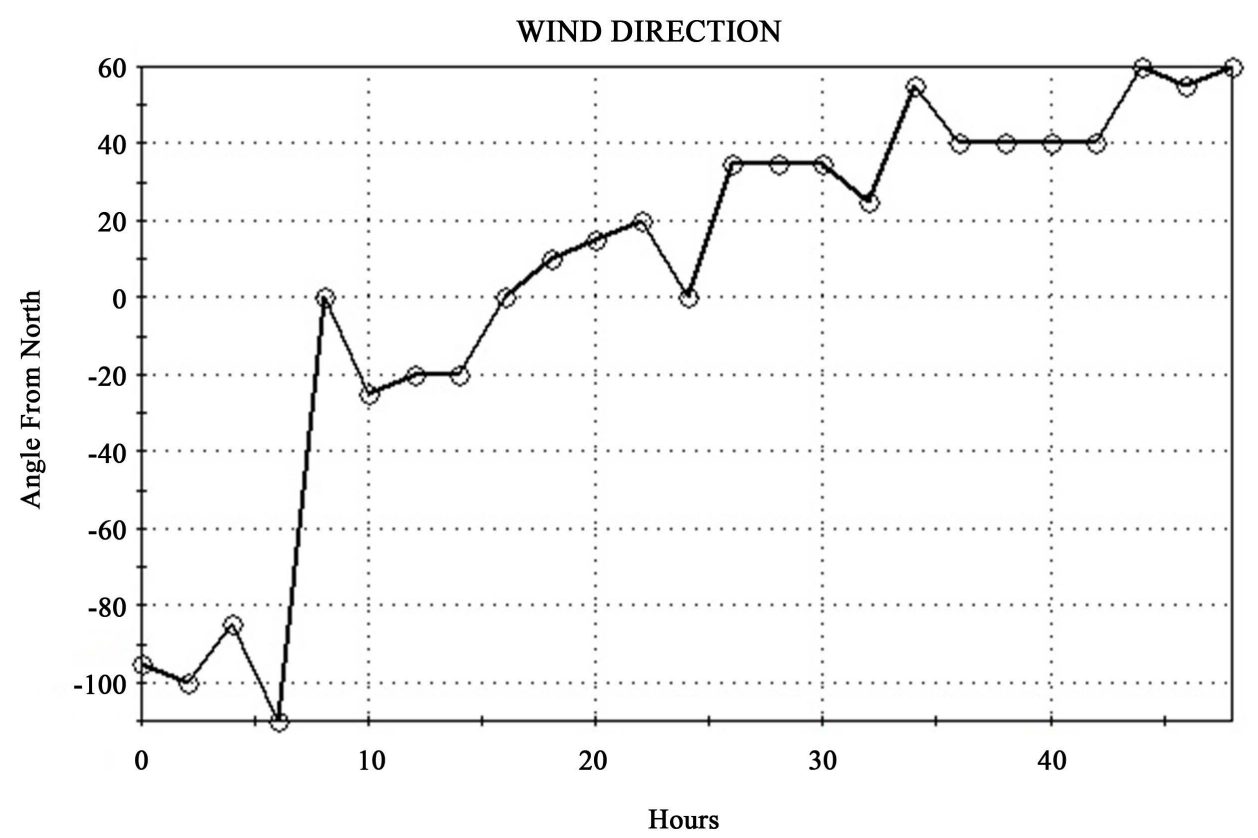

Figure 2. Same as for Figure 1 except for wind direction.

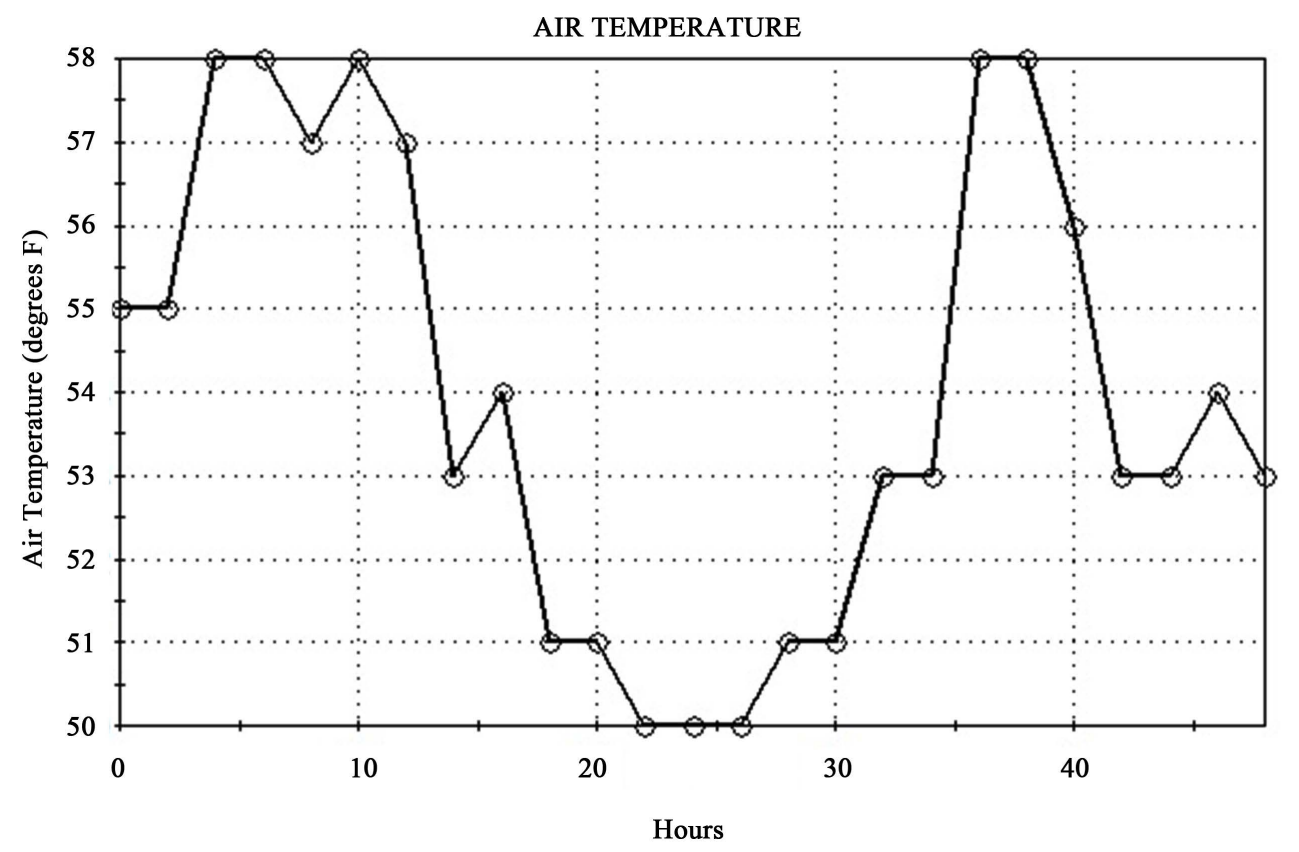

Figure 3. Same as for Figure 1 and Figure 2 except for dry bulb air temperature.

\section{DISCUSSION}

To compare with the dynamical equation, horizontal current shear equals the Coriolis parameter, at $35^{\circ} \mathrm{N}$ the Coriolis parameter is about 8.3 times 10 to the minus 5 per sec. An estimate of the current shear of the wind based on Figure 1 is 7.1 times 10 to the minus 5 per sec. For this shear estimate the mean change in wind speed is taken to be $25 \mathrm{kts}$ over the distance of two degrees of longitude at $35^{\circ} \mathrm{N}$, or 182 $\mathrm{km}$. There is not perfect agreement but that was not expected. The estimated shear is the same order of magnitude as the Coriolis parameter although it is smaller. A few factors have not yet been considered. 
First, the ship moved west towards the storm and the storm drifted east toward the ship. Both movements should cause the estimated shear to be larger than it really was. How much larger is not completely known even though a good estimate of the average ship's westward speed during the storm can be made with the information available. What is missing is a good handle on the eastward drift speed of the storm itself.

Second, the ship's track made a sizeable angle to the direction of the mean flow of the wind, as indicated by Figure 2, and it is likely that the direction of maximum shear should be perpendicular to the mean flow, as assumed in the dynamical equation. That effect would significantly decrease the estimate of the shear compared to what it really was. Two different effects compete because they have opposite signs.

\section{CONCLUSION}

A dynamical equation; horizontal wind shear equals the Coriolis parameter; obtained earlier by combining Bernoulli's law with the geostrophic relation, is evaluated with routine meteorological data from an oceanographic ship whose track along $35^{\circ} \mathrm{N}$ intersected that of a wind storm. Both sides of the equation agree in sign and order of magnitude. Rather than standing alone this result should in the future join other comparisons between theory and measurement.

\section{CONFLICTS OF INTEREST}

The author declares no conflicts of interest regarding the publication of this paper.

\section{REFERENCES}

1. Kenyon, K.E. (1996) Bi-Daily Variation of Meteorological Properties at Sea Level across the Pacific along $35^{\circ} \mathrm{N}$. Atmospheric Research, 43, 31-56. https://doi.org/10.1016/S0169-8095(96)00003-8

2. Kenyon, K.E. (2018) Bernoulli Weather or Not? Natural Science, 10, 178-181. https://doi.org/10.4236/ns.2018.105019

3. Kenyon, K.E. (2019) Flow past a Sphere. Natural Science, 11. 